\title{
Commentary: Tell me a story
}

\author{
Eugene H. Blackstone, MD
}

What Bodies are expanded by being frozen, and how that expansion is evinced? And whether it is caused by the intrusion of Air? As also, what is contained in icy bubbles is true and Springy Air, or not? ${ }^{l}$

What makes the wispy clouds of vapor rising from your cup of hot coffee? Or the puffy white clouds hovering in the sky? What keeps Jell-O's water from oozing out? And why don't your joints squeak? ${ }^{2}$

Rarely is the story behind scientific discovery revealed in exciting prose as was the discovery of the gas laws ("Springy Air") by Robert Boyle or the fourth (liquid crystal) phase of water $\left(\mathrm{H}_{3} \mathrm{O}_{2}\right.$, not $\left.\mathrm{H}_{2} \mathrm{O}\right)$ by Gerald Pollack, thanks to Pasteur's rigid structure of scientific papers for selective, strategic reading ${ }^{3}$ :

Introduction

What is the problem?

Why is it important?

What approach have I taken to address the problem?

Methods

What I did.

Results

What I found (facts only).

Discussion

What I think it means.

This structure is neither prose nor poetry. Nevertheless, if one keeps in mind storytelling, a scientific paper will be coherent and contain all the essential pieces (and avoid extraneous material) in an orderly, consistent manner, all neatly tied together.

From Heart, Vascular, and Thoracic Institute, Cleveland Clinic, Cleveland, Ohio. Disclosures: The author reported no conflicts of interest.

The Journal policy requires editors and reviewers to disclose conflicts of interest and to decline handling or reviewing manuscripts for which they may have a conflict of interest. The editors and reviewers of this article have no conflicts of interest.

Received for publication Nov 2, 2020; revisions received Nov 2, 2020; accepted for publication Nov 3, 2020; available ahead of print Nov 7, 2020.

Address for reprints: Eugene H. Blackstone, MD, Department of Thoracic and Cardiovascular Surgery, Cleveland Clinic/Desk JJ40, 9500 Euclid Ave, Cleveland, OH 44195 (E-mail: blackse@ccf.org).

J Thorac Cardiovasc Surg 2022;164:182-3

$0022-5223 / \$ 36.00$

Copyright (c) 2020 by The American Association for Thoracic Surgery

https://doi.org/10.1016/j.jtcvs.2020.11.011

In "Recruitment maneuvers to reduce pulmonary atelectasis after cardiac surgery: a meta-analysis of randomized trials," ${ }^{4}$ all the required pieces of a meta-analysis PRISMA (Preferred Reporting Items for Systematic Reviews and Meta-Analyses) checklist are present, but to be a pleasure to read and understand, how much better it would be if it told a story.

Dr Thomas Rice was the champion of the 3-sentence Introduction-what is the problem, why is it important, what approach is taken to study the problem (objectives). In $\mathrm{Hu}$ and colleagues' very long Introduction, with a bit of patience one can ferret out the problem and its importance. In the final sentence, they do provide an organizational structure for their investigation and at least an implied hypothesis (to compare efficacy and safety of recruitment maneuvers with conventional mechanical ventilation in reducing atelectasis and hypoxic events in patients undergoing cardiac surgery). From this, the reader should expect under Results and Discussion 2 important efficacy end points-atelectasis and hypoxic events-and a comparison of maneuvers. But what is the measure of safety? So, despite the Introduction's length, which should completely set up the story, it is incomplete.

Thus, like $80 \%$ of readers, I skip Materials and Methods and dive into Results, where I am stopped short: Trial Characteristics. Is this a Result? Or should this be near the beginning of Material and Methods? After all, a meta-analysis is an observational study of literature. The research subjects are papers, the 
"Material" part of Material and Methods. Without these crucial details, it is hard to evaluate important aspects of Methods.

Back to Results. I now find the comparative incidence of pulmonary atelectasis and hypoxia. But then I encounter the subtitles $\mathrm{PaO}_{2} / \mathrm{FiO}_{2}$ Ratio, Cardiac Index, Mean Arterial Pressure, Postoperative Complications, and Grading Evidence Quality. Where do these belong in the story? I find some clues in the next to last paragraph of the Discussion: These relate to safety! In the introduction to the story, wouldn't a simple clause such as, "without hemodynamics deterioration" or some explicit clause about safety alert me to what was coming? Might the sign posts under Results have been "Efficacy" and then "Safety"? That would provide a coherent, linear story.

But what about "Grading Evidence Quality" tacked onto the end of Results? That is important, as are a number of other details essential for a high-quality meta-analysis. Placing them at the end of Results, however, disrupts the story. This is what "Supplemental Material" is for!
In sum, be it a complex meta-analysis, clinical trial, observational study, or translational science study - all with potentially many moving parts-readers are more likely to "get it" and appreciate it if they can seamlessly go from a brief Introduction to Methods to Results to Discussion to Clinical Implications to Conclusions with a story that fastidiously follows a logical roadmap laid out in the Introduction. A scientific paper may never be prose, like that of Boyle and Pollack, but our papers can be a little more readable, logically ordered, and follow the themes if we think about storytelling.

\section{References}

1. A further account of Mr. Boyle's experimental history of cold. Philos Transact. 1665;1 46-52. Available at: http://www.jstor.org/stable/101423. Accessed November 30, 2020.

2. Pollack GH. The Fourth Phase of Water: Beyond Solid, Liquid, and Vapor. Seattle: Elger and Sons; 2013.

3. Hu MC, Yang YL, Chen TT, Lee CI, Tam KW. Recruitment maneuvers to reduce pulmonary atelectasis after cardiac surgery: a meta-analysis of randomized trials. J Thorac Cardiovasc Surg. 2022;164:171-81.e4.

4. Day RA. The origins of the scientific paper: the IMRAD format. AMWA J. 1989;4:16-8.

\section{See Article page 171}

\section{Commentary: Lung recruitment: Why is this not on my radar?}

\author{
Fraser D. Rubens, MD, MSc, FACS, FRCSC
}

Perioperative management topics cycle in morbidity and mortality rounds with a degree of regularity. As surgeons, we generally focus on those issues that we can control, as well as those for which we have an understanding of the physiology. Nonetheless, some topics fall through the cracks, never seeing the light of day and not being considered priorities.

In this article of the Journal, Hu and colleagues ${ }^{1}$ present a meta-analysis reviewing lung recruitment, admirably attempting to cobble together a series of articles peppered with heterogeneity and ultimately highlighting the potential importance of this topic to all of us. This is a thoughtful

\footnotetext{
From the Division of Cardiac Surgery, University of Ottawa Heart Institute, Ottawa, Ontario, Canada.

Disclosures: The author reported no conflicts of interest.

The Journal policy requires editors and reviewers to disclose conflicts of interest and to decline handling or reviewing manuscripts for which they may have a conflict of interest. The editors and reviewers of this article have no conflicts of interest.

Received for publication Nov 8, 2020; revisions received Nov 8, 2020; accepted for publication Nov 11, 2020; available ahead of print Nov 20, 2020

Address for reprints: Fraser D. Rubens, MD, MSc, FACS, FRCSC, Ottawa Heart Institute, 40 Ruskin St, Ottawa, Ontario, Canada K1Y 4W7 (E-mail: frubens@ ottawaheart.ca).

J Thorac Cardiovasc Surg 2022;164:183-4

0022-5223/ $\$ 36.00$

Copyright (c) 2020 by The American Association for Thoracic Surgery

https://doi.org/10.1016/j.jtcvs.2020.11.034
}

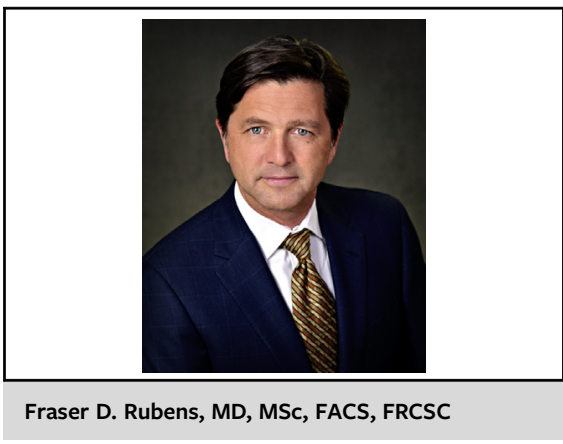

CENTRAL MESSAGE

If we have the patience and the wherewithal, we can identify the simplest interventions we take for granted that can improve our patients' lives.

academic achievement, as there were several leaps of faith to amalgamate these papers into a coherent message. The question of lung recruitment is hampered by a lack of consensus on many issues. Clearly, the hypothesis supporting the positive benefits of this strategy has a vague 